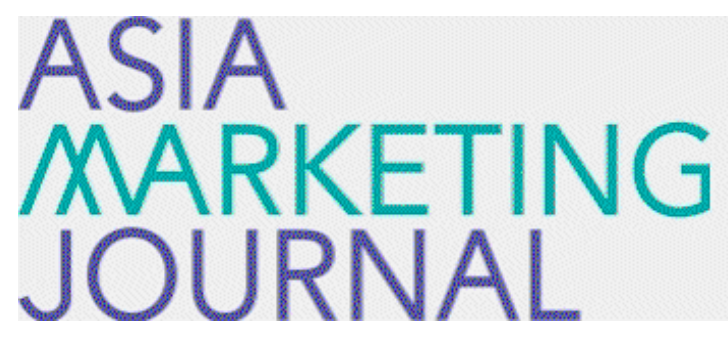

ASIA MARKETING JOURNAL

Volume 15 | Issue 2

Article 5

7-30-2013

\title{
Differences in Reactions to Sales Promotions
}

Chang Soo Kim

Myung Soo Jo

Follow this and additional works at: https://amj.kma.re.kr/journal

Part of the Marketing Commons

\section{Recommended Citation}

Kim, Chang Soo and Jo, Myung Soo (2013) "Differences in Reactions to Sales Promotions," Asia Marketing Journal: Vol. 15 : Iss. 2 , Article 5.

Available at: https://doi.org/10.53728/2765-6500.1520

This Article is brought to you for free and open access by Asia Marketing Journal. It has been accepted for inclusion in Asia Marketing Journal by an authorized editor of Asia Marketing Journal. 


\section{Differences in Reactions to Sales Promotions: Superior or Inferior to Your Product?}

Chang Soo Kim* Myung-Soo Jo**

This study examines whether product promotions are influenced by the market standing of promoted products, using social comparison theory (upward versus downward comparisons). It is hypothesized that people in possession of a product that is inferior to the one on promotion express less discomfort about the promotion and use the information more than do people in possession of a superior product. People in possession of an inferior product may also exhibit more positive attitudes toward the product on promotion, but may show poorer attitudes toward their own possessed product than do people with a superior product. This is because people in an inferior socioeconomic position show a strong motivation to improve themselves through upward social comparison, whereas people in a superior socioeconomic position maintain a strong sense of superiority in downward social comparison, which suggests strong endowment effects.

The findings mainly support the hypotheses, and suggest that sales promotions are more effective for people who currently own an inferior product, but not for people with a superior product, who have a strong motivation to maintain their sense of superiority. The findings also imply that, in order to attract consumers in the superior market, managers for inferior products need to turn to methods other than sales promotions, which may include introducing a new brand or sub-brand, or emphasizing luxury and modern features. In contrast, managers for superior products may emphasize product functions and attributes of superior products in their promotions, as people with inferior products may consider such information as benefits of the superior products.

Key words: downward and upward social comparison, contradiction of endowment effects, sales promotion

\footnotetext{
* Marketing Instructor. Hankuk University of Foreign Studies(changsookim@daum.net). The First Author

** Professor. Desautels Faculty of Management McGill University(myung-soo.jo@mcgill.ca), Corresponding Author
} 


\section{Introduction}

When people are faced with a promotion, they tend to respond positively or negatively toward it. These reactions could be a result of being exposed to different levels of product quality (Hong et al. 2012), price (Im 2012: Park 2011), or other features. That is, a product's market position may lead people to judge the promotion and behave accordingly, such as forming certain attitudes and purchasing the product. For example, a high-quality brand's price reduction brings about increasing sales (e.g.. switching), whereas a low-quality brand's price reduction is less likely to bring about the same result (i.e., asymmetric quality tier competition: Blattberg and Wisniewski 1989: Sivakumar and Raj 1997).

This study suggests that when people are exposed to the promotion of a product in different market positions (i.e., a superior versus inferior position), they may compare their owned products with the promoted one, and may evaluate the position of their owned products. Hence, the market position of their owned product may result in a differential influence for the promoted product. If the market position of people's owned product can influence people's reactions to the promotion, a product's market position may play a role as an attribute of the product in the context of promotion. This may lead people to form asymmetric atti- tudes toward the owned versus the promoted product, such as increasing or decreasing positive attitudes, based on their product's market position.

This study demonstrates people's different responses toward their own and promoted products, depending on the market position of their own product. Specifically, based on social comparison theory and endowment effects, the study examines the effectiveness of product promotions for different market positions.

\section{Literature Review}

\subsection{Social Comparison Theory}

According to social comparison theory (Argo, White, and Dahl 2006: Festinger 1954), people often obtain information about their own performance by processing a comparison of themselves with others. Such comparisons can take two forms: upward (i.e., comparison with someone in a superior condition) and downward (i.e., comparison with someone in an inferior condition; Argo et al. 2006: Wheeler 1966; Wills 1981). Upward social comparison may be especially helpful when people desire to improve their standing because it can provide concrete information about superiors, which can offer inspiration and can instill motivation within people in an inferior condition (Taylor and Lobel 
1989: Taylor, Neter, and Wayment 1995: Wood 1989: Wood and Taylor 1991). This process is particularly acute when people reside in an inferior condition because they tend to recognize the motivation to improve and upgrade themselves by engaging in comparisons with others in a superior condition (e.g., ideal reference groups: Collins 1996: Wheeler 1966).

In contrast, downward social comparisons may be more salient in a superior versus an inferior condition because in the former case, people tend to compare themselves with others in an inferior condition to increase their own positive feelings, such as their sense of superiority. The theory of downward social comparison posits that people who experience negative affect can enhance their subjective well-being by comparing themselves to less fortunate others (Aspinwall and Taylor 1993: Bonifield and Cole 2008). This prediction receives research support, in that downward social comparisons reduce anger, improve post-purchase behavioral attitudes (Bonifield and Cole 2008), and increase self-evaluations (Collins 1996: Wills 1981).

\subsection{Diagnosticity}

Diagnosticity is developed from the accessibility-diagnosticity model (Feldmand and Lynch 1988: Lynch, Marmorstein, and Weigold 1988), and is defined as an evaluation and belief about the usefulness of information for one's prediction in information processing (e.g., judgment;
Jiang and Benbasat 2005: Russo, Meloy, and Medvec 1998). In other words, it is the motivation to consider the usefulness of information in decision-making. Previous researchers suggest an interaction between diagnosticity and non-diagnosticity (e.g., the dilution effect, Kemmelmeier 2004), the relation between diagnosticity and distortion (Russo et al. 1998), the relation between the diagnosticity of advertising and brand attitude (Baker 2001), and so on. For example, a high level of informational diagnosticity is likely to decrease the level of distortion toward the information (Russo et al. 1998). Diagnosticity is likely to approximate relevance because of prejudgment via motivated reasoning. Since people already have prejudgments toward objects, they consider information that is consistent with their prejudgments because consistent information can create a positive effect for such prejudgments.

Diagnosticity can be related to endowment effects, such as endowment versus the lack of an endowment effect due to ownership of a product. Put differently, diagnosticity may positively or negatively influence individual attitudes toward their own products, depending on the ownership of a superior versus an inferior product.

\subsection{Endowment and Non-Endowment Effects}

Sellers want to sell their products at a high 
price, whereas buyers want to purchase products at a low price. Previous researchers explain these behaviors through the endowment effect via loss aversion (Carmon and Ariely 2000: Kahneman, Knetsch, and Thaler 1990: Kahneman and Tversky 1979: Knetsch and Sinden 1984: Zhang and Fishbach 2005). In detail, endowment effects pertain to the increased perceived value of an object when that object becomes part of the person's own endowment (Kahneman, Knetsch, and Thaler 1991: Thaler 1980) - that is, people place a higher value on products they own than on products they do not.

However, endowment effects are not necessarily caused by ownership, which has traditionally been assumed to be a required factor of the endowment effect. That is, we infer a contradiction of the endowment effect, in which people are less likely to over-evaluate the value of their own product. This tendency can be created by people's position, such as a superior versus subordinate position. If a superior position leads superior product owners to compare themselves with a promoted inferior product, due to a bias toward the promoted product via motivated reasoning (Jain and Maheswaran 2000: Kunda 1999), they may not accept the above-mentioned promotion's benefits, and their attitude may depend on the ownership of the product as an endowment effect. In contrast, if an inferior position leads inferior product owners to compare themselves with a superior product, people may concentrate on the value of other superior products because they already know about their own product's limitations as an inferior product. Hence, people who own inferior products may over-evaluate superior positioners' promotions.

Accordingly, superior product owners' downward comparisons may create an endowment effect toward their own product, whereas inferior product owners' upward comparisons may bring about the absence of an endowment effect toward their owned product.

\section{Hypotheses}

If people who are in an inferior condition use an upward comparison to improve and upgrade their status (Taylor et al. 1995), they may not feel discomfort in response to the promotion of a superior product (e.g., a free upgrade for BMW owners). Because of the superiority of a product on promotion and motivated reasoning (Jain and Maheswaran 2000: Kunda 1999), inferior owners already wish to be part of that superior condition, and would benefit even more from the promotion in their effort to attain that level. In contrast, people in the superior condition (e.g., BMW owners), who are likely to use downward comparisons to increase their self-evaluation (self-evaluation maintenance model: Collins 1996: Tesser, Millar, and Moore 1988: 
Wills 1981) or to maintain their sense of superiority (self-enhancement: Taylor et al. 1995: Wills 1981), may view the promotion of an inferior product (e.g., a free upgrade for Hyundai owners) with discomfort because the beneficial and attractive promotion appears to threaten their own sense of superiority (see Figure 1 for a summary of the hypotheses). In other words, because an attractive promotion of an inferior product that superior product owners do not have can signify a loss for themselves via loss aversion, the promotion of an inferior product can lead owners of superior products to experience negative feelings. Thus:

H1a: People with an inferior product will not feel a higher level of discomfort over a superior product after being exposed to the superior product's promotion. However, people with a superior product will show a higher level of discomfort over an inferior product after being exposed to the inferior product's promotion.

Exposure to the promotion of a superior product (e.g., a free upgrade for BMW owners) may cause people who possess an inferior product to feel high discomfort about their ownership of an inferior product (e.g., Hyundai ownership). Specifically, they are aware of their product's position in the market because they tend to compare themselves with other people, and they may focus on the benefits of a superior product due to a sense of loss
(Kahneman and Tversky 1979). For example, they cannot access the promotion for the superior product, which suggests a conflict with the prediction of the endowment effect (Kahneman, Knetsch, and Thaler 1990: Thaler 1980). In other words, a superior product's benefits can influence people with an inferior product 1) to recognize their position in the market: 2) to accept the value of their product as low because of its inferior market position: and 3) to feel uncomfortable toward their own product. Hence, the superior product's promotion can lead people with an inferior product to experience a contradiction of endowment effects.

However, people who possess a superior product (e.g.. a BMW car) may not sense any real discomfort about their ownership of a superior product, even when they recognize a promotion for an inferior product (e.g., free radial tires for Hyundai owners). The downward social comparison in which they engage likely offers a strong demonstration of endowment effects, instead. The endowment effect, thus, may play a defensive role, working to maintain positive self-evaluations in this case (Collins 1996: Tesser et al. 1988: Wills 1981). That is, their lack of discomfort regarding their ownership of the superior product helps them maintain their positive feelings, such as their sense of superiority (see Figure 1). Thus:

H1b: People with an inferior product will show a higher level of discomfort over their 
own product after being exposed to a superior product's promotion. However, people with a superior product will not feel a higher level of discomfort over their own product after being exposed to an inferior product's promotion.

Those who possess an inferior product may also process the information of both promotions more diagnostically than do people with a superior product because they are more motivated to acquire the promoted product in order to fulfill their goal of self-improvement. In contrast, those with a superior product are more likely not to be interested in analyzing the promotion information about an inferior product because it is inconsistent with their main interest. Diagnosticity is based on relevance: more specifically, it is consistent or inconsistent information, and represents the sufficiency of the retrieved information for the judgment task at hand (Menon, Raghubir, and Schwarz 1995). For owners of a superior product, the promotion of an inferior product can be irrelevant and inconsistent information with their expectation, and superior product owners may be less likely to consider the promotion in their information processing. Furthermore, because the sales promotion threatens to decrease their self-evaluation, people who possess a superior product may avoid or ignore such a promotion in order to maintain their sense of superiority, as in the status quo (Chernev 2004). This tendency will result in a low level of diagnosticity. Thus, (see Figure 1):

H2: People with an inferior product will process promotion information more diagnostically than will people with a superior product.

People who have an inferior product may also distort promotion information less than people with a superior product because they tend to feel less discomfort about the information in the promotion, and they may want to obtain the superior product. In contrast, people with a superior product may be likely to distort the promotion of an inferior product due to its inconsistency with their interest and their defensive goal of maintaining a sense of superiority. In addition, they want to reduce the discomfort they feel due to the promotion of the inferior product. Previous research shows that people have preexisting preferences to distort information in order to favor their preferred alternatives (Russo, Medvec, and Meloy 1996: Russo, Meloy, and Medvec 1998): thus, as the diagnosticity of the information increases, the distortion of that information decreases. In turn, we expect the relationship of information distortion to be opposite of that predicted in $\mathrm{H} 2$ (see Figure 1):

H3: People with an inferior product will distort promotion information less than do people with a superior product. 


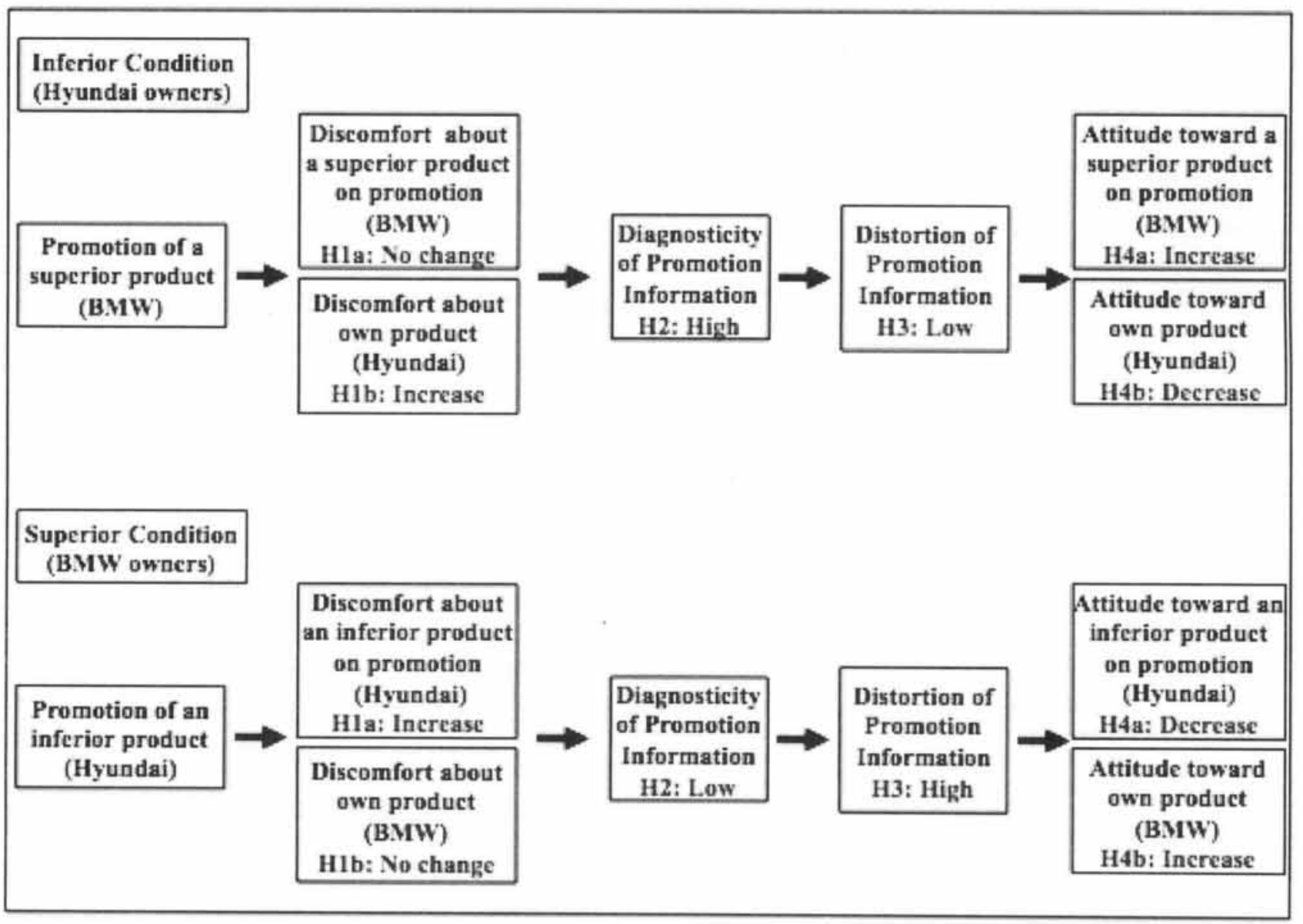

We also posit that people with an inferior product exhibit improved attitudes toward the superior promoted product. That is, people with an inferior product improve their attitudes toward the superior product when exposed to the promotion because of their desire to acquire the superior product in the course of their upward social comparison. This desire becomes manifest in the level of discomfort and the distortion of the promotion information, as discussed previously. However, people with a superior product may exhibit more negative attitudes toward the inferior product on promotion because they wish to maintain their sense of superiority due to their possession of the superior product. This effect may occur through their downward social comparison as an outcome of endowment effects. Thus:

H4a: People with an inferior product will increase their positive attitudes toward a superior promoted product. However, people with a superior product will decrease their positive attitudes toward an inferior promoted product.

As a reflection of their upgraded desire, peo- 
ple in possession of an inferior product may also experience decreased positive attitudes toward their own product when they view the promotion of a superior product, in contrast with the predictions of endowment effects. The elevated desire for self-improvement might result from upward social comparison induced by the promotion of a superior product. However, people with a superior product may improve their attitudes toward their own product when they see an inferior product promotion as a result of their defensive goal to maintain their sense of superiority based on their possession, which reflects a strong manifestation of endowment effects. Thus:

H4b: People with an inferior product will decrease their positive attitudes toward their own inferior product when exposed to the promotion of a superior product. However, people with a superior product will increase their positive attitudes toward their own superior product when exposed to the promotion of an inferior product.

\section{Method}

\subsection{Pretest}

We selected ten automobile brands from a valuation Website associated with the Kelley
Blue Book (www.kbb.com) and asked 24 Canadian subjects to provide their quality and familiarity (i.e.. good/bad, not familiar/familiar) ratings on seven-point scales. The quality ratings suggested BMW (mean $=6.47$ ) as a superior car and Hyundai (mean $=4.00$ ) as an inferior one, and the subjects showed high familiarity with both brands. On the basis of in-depth interviews, we next identified five automobile features that could be upgraded, then tested the diagnosticity that these five features would offer (i.e., useful, relevant, helpful) if they were provided for free by the automotive company. The findings support the selection of radial tires (mean $=4.38$ ) as a feature that would be an effective promotion.

\subsection{Hypotheses Testing}

The subjects first received a priming scenario (i.e., "You are very satisfied with your automobile ownership of a BMW [Hyundai]"). then they were primed again by a request that they list the items they wished their current car (BMW or Hyundai) would have. On the next page of the experimental booklet, they considered a sales promotion that opposed their hypothetical car ownership (e.g., a BMW sales promotion for Hyundai owners versus a Hyundai sales promotion for BMW owners). This stimulus read, "If you purchase a Hyundai (BMW) car, you can take advantage of a Free Upgrade offered by Hyundai (BMW). Hyundai (BMW) 
will give you Free New Radial Tires." Subjects indicated their discomfort (uneasy, uncomfortable, bothered: Elliot and Devine 1994) and attitudes toward their own car and the promoted car (likeable, favorable, good: Aaker 2000) on seven-point scales, both before and after reading the sales promotion. They also rated the diagnosticity of the information contained in the sales promotion (useful, relevant, helpful: Ahluwalia 2000: Ahluwalia, Burnkrant, and Unnava 2000: Kemmelmeier 2004) on sevenpoint scales. To measure the level of distortion associated with processing the promotion information, we used open-ended questions that asked the subjects to describe their thoughts about the presented promotion information (Jain and Maheswaran 2000). Furthermore, to avoid any order effects, the two types of questionnaires (Hyundai ownership with BMW promotion, and vice-versa) were presented alternately to the subjects.

\section{Results}

We recruited 121 subjects from a major shopping mall located in a large Canadian metropolitan city. The subjects represent both genders equally and are relatively young (average age of 22 years). In the manipulation check, as expected, the findings show that the subjects exhibit higher levels of positive attitudes for the BMW than for the Hyundai $\left(\mathrm{M}_{\mathrm{BMW}}=\right.$ 5.91, $\mathrm{M}_{\text {Hyundai }}=3.89, p<.01$ ). Subjects in both the superior and inferior product conditions also reveal similar attitudes toward both the BMW $\left(\mathrm{M}_{\text {Superior }}=6.0, \mathrm{M}_{\text {Inferior }}=5.83, p>.5\right)$ and the Hyundai $\left(\mathrm{M}_{\text {superior }}=3.93, \mathrm{M}_{\text {Inferior }}=3.85, p>5\right)$, which confirms that the manipulation worked, as we intended. All of the items reveal strong reliability (over Cronbach's $a=.80$ ).

Subjects who possessed an inferior product (Hyundai car) felt a little discomfort about the BMW on promotion, and their discomfort level did not change significantly before or after their exposure to the promotion $\left(\mathrm{M}_{\text {Before }}=2.43\right.$, $\mathrm{M}_{\text {After }}=2.44: p>.5$ ), whereas those who possessed the superior product (BMW) expressed higher levels of discomfort about the Hyundai after they read about the promotion $\left(\mathrm{M}_{\text {Before }}=\right.$ 2.94, $\mathrm{M}_{\text {After }}=3.69, p<.01$ ), in strong support of Hla. As H1b predicts, people in possession of the inferior product (Hyundai) claimed higher levels of discomfort about their own product after exposure to the BMW promotion ( $\mathrm{M}_{\text {Before }}$ $\left.=2.85, \mathrm{M}_{\text {After }}=3.56: p<.05\right)$. In contrast, subjects in possession of the superior product (BMW) did not feel a higher level of discomfort about their own product (BMW), even after exposure to the Hyundai promotion $\left(\mathrm{M}_{\text {Before }}=\right.$ 2.29. $\mathrm{M}_{\text {After }}=2.13: p>$.1) (see Figure 2). As we hypothesized in $\mathrm{H} 2$, people in possession of the inferior product (Hyundai) processed the promotion information more diagnostically than did people in possession of the superior product 
$\left(\mathrm{M}_{\text {Inferior }}=3.21, \mathrm{M}_{\text {Superior }}=2.41: p<.01\right)$.

To test H3, two judges coded the subjects' opinions, collected by the open-ended questions, into four categories: distortion, agreement, ignorance, and irrelevant opinions. For example, a distortion opinion might state, "Probably, the car company has some problems," whereas an agreement opinion could be, "The promotion is good for people who want to buy a car." An example of an ignorance opinion is, "I have no idea," and an irrelevance opinion expresses a sense that "the promotion does not compare

〈Figure 2〉 Findings of Hypotheses 1 and 4

Discomfort about product on promotion (Hla)

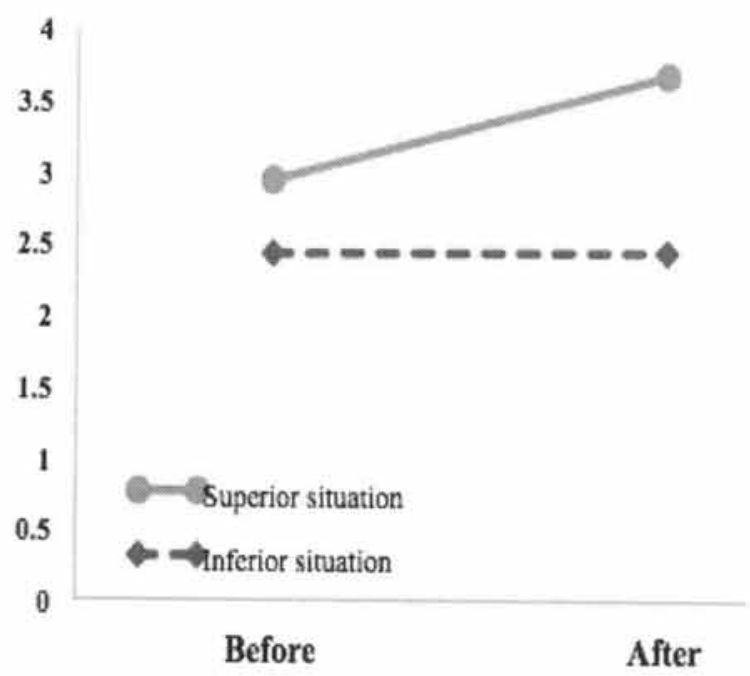

Exposure of promotion

Attitude toward product on promotion ( $\mathrm{H} 4 \mathrm{a}$ )

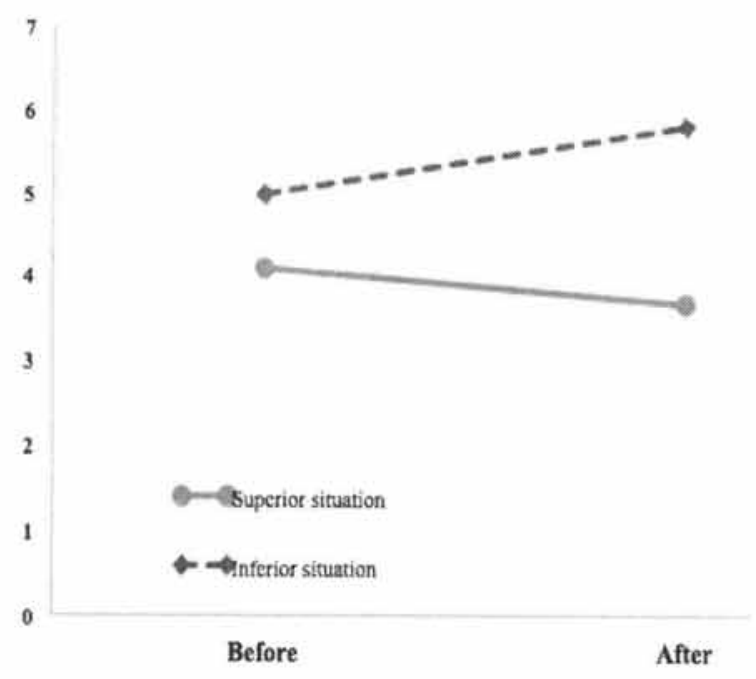

Exposure of promotion
Discomfort about own product (H1b)

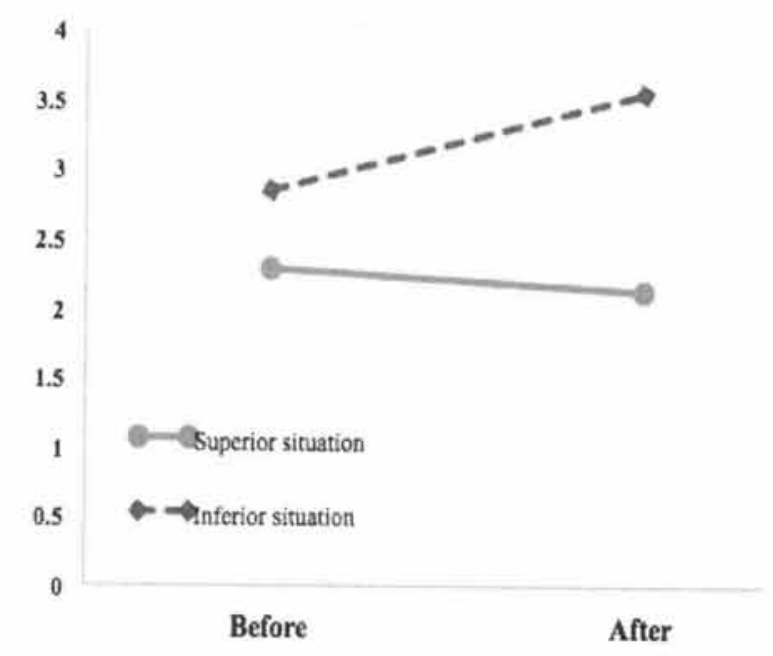

Exposure of promotion Attitude toward own product (H4b)

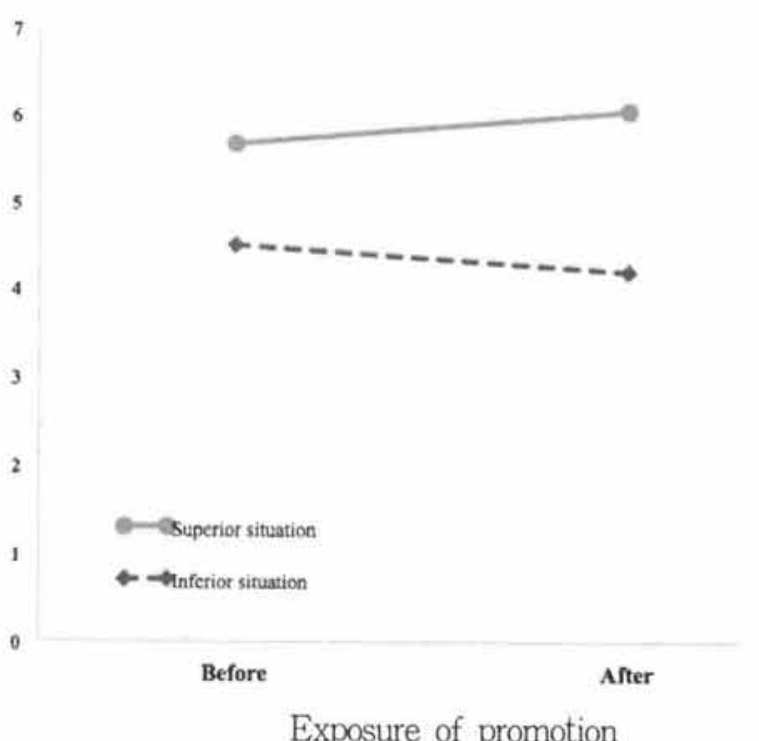


with my car." We dichotomized the responses into distortion versus nondistortion (i.e., agreement, ignorance, and irrelevant) comments to test for $x^{2}$. As hypothesized, people in possession of the inferior product (Hyundai) distorted the promotion information less than did people in possession of the superior product (inferior situation, 12 subjects, 9.9\% distortion rate: superior situation, 35 subjects, $27.3 \%$ distortion rate: $\left.x^{2}(1)=16.16, p<.01\right)$. The findings thus strongly support H3: people with an inferior product distort promotion information less than do those in possession of a superior product (see Table 1).

〈Table 1〉 Hypotheses Findings

\begin{tabular}{|c|c|c|c|c|}
\hline Discomfort (H1) & Exposure & Mean & $\mathrm{SD}$ & $\mathrm{P}$ \\
\hline \multirow{2}{*}{$\begin{array}{l}\text { About BMW } \\
\text { by Hyundai Owners }\end{array}$} & Before & 2.43 & 1.52 & \multirow{2}{*}{.96} \\
\hline & After & 2.44 & 1.64 & \\
\hline \multirow{2}{*}{$\begin{array}{l}\text { About Hyundai } \\
\text { by BMW Owners }\end{array}$} & Before & 2.94 & 1.28 & \multirow{2}{*}{.01} \\
\hline & After & 3.69 & 1.68 & \\
\hline \multirow{2}{*}{$\begin{array}{c}\text { About Hyundai } \\
\text { by Hyundai Owners }\end{array}$} & Before & 2.85 & 1.31 & \multirow{2}{*}{.01} \\
\hline & After & 3.56 & 1.66 & \\
\hline \multirow{2}{*}{$\begin{array}{c}\text { About BMW } \\
\text { by BMW Owners }\end{array}$} & Before & 2.29 & 1.41 & \multirow{2}{*}{.49} \\
\hline & After & 2.13 & 1.47 & \\
\hline Diagnosticity (H2) & Mean & \multicolumn{2}{|c|}{ SD } & $\mathrm{P}$ \\
\hline \multirow{2}{*}{$\begin{array}{c}\text { Hyundai Owners } \\
\text { BMW Owners }\end{array}$} & 3.21 & \multicolumn{2}{|c|}{1.84} & \multirow{2}{*}{.01} \\
\hline & 2.41 & \multicolumn{2}{|c|}{1.40} & \\
\hline Distortion (H3) & Distortion & \multicolumn{2}{|c|}{ Non-distortion } & Sum \\
\hline BMW Owners & $33(27.3 \%)$ & \multicolumn{2}{|c|}{$27(22.3 \%)$} & 60 \\
\hline Hyundai Owners & $12(9.9 \%)$ & \multicolumn{2}{|c|}{$49(40.5 \%)$} & 61 \\
\hline Sum & $45(37.2 \%)$ & & & 121 \\
\hline \multicolumn{5}{|l|}{ - $x^{2}(1)=16.16, \mathrm{p}=.00$} \\
\hline Attitude (H4) & Exposure & Mean & SD & $\mathrm{P}$ \\
\hline \multirow{2}{*}{$\begin{array}{c}\text { Toward BMW } \\
\text { by Hyundai Owners }\end{array}$} & Before & 4.98 & 1.37 & \multirow{2}{*}{.00} \\
\hline & After & 5.81 & 1.23 & \\
\hline \multirow{2}{*}{$\begin{array}{l}\text { Toward Hyundai } \\
\text { by BMW Owners }\end{array}$} & Before & 4.08 & 1.31 & \multirow{2}{*}{.04} \\
\hline & After & 3.67 & 1.47 & \\
\hline \multirow{2}{*}{$\begin{array}{l}\text { Toward Hyundai } \\
\text { by Hyundai Owners }\end{array}$} & Before & 4.45 & 1.23 & \multirow{2}{*}{.01} \\
\hline & After & 4.19 & 1.40 & \\
\hline \multirow{2}{*}{$\begin{array}{l}\text { Toward BMW } \\
\text { by BMW Owners }\end{array}$} & Before & 5.66 & .78 & \multirow{2}{*}{.02} \\
\hline & After & 6.06 & .91 & \\
\hline
\end{tabular}


People with the inferior product also expressed a higher level of positive attitude toward the superior product (BMW) when they were exposed to the promotion of the superior product $\left(\mathrm{M}_{\text {Betore }}=4.98, \mathrm{M}_{\text {After }}=5.81: p<\right.$ .01 ), whereas people with the superior product expressed a lower level of positive attitude toward the inferior product (Hyundai) after exposure to its promotion $\left(\mathrm{M}_{\text {Before }}=4.08, \mathrm{M}_{\text {After }}\right.$ $=3.67: p<.01$ ), in support of H4a (see Table 1). Moreover, people with the inferior product expressed a similar level of positive attitude toward their own product (Hyundai) after seeing the promotion of the superior product $\left(\mathrm{M}_{\text {Before }}\right.$ $=4.45, \mathrm{M}_{\text {After }}=4.19, p>1$ ), but those with the superior product showed a higher level of positive attitude toward their own product (BMW) after seeing the promotion of the inferior product $\left(\mathrm{M}_{\text {Before }}=5.66, \mathrm{M}_{\text {After }}=6.06: p\right.$ $<.01$ ), which offers partial support for H4b (see Figure 2).

\section{Implications}

People's reactions to sales promotions depend strongly on their situation. Specifically, they react very differently, depending on their superior versus inferior position and ownership versus nonownership status, both of which create different levels of discomfort and attitudes toward their own product and the product on promotion. Our findings, therefore, suggest that the promotion of a superior product can bring about positive reactions toward superior product owners and for people who do not have the product, whereas a promotion for an inferior product, specifically speaking, is not effective for owners who have the product. Thus, this study offers valuable guidelines regarding the appropriate targets for sales promotions.

In this regard, our findings have both managerial and theoretical implications. The findings in the inferior product condition contradict the predictions associated with endowment effects, which would imply that people place a higher value on the products they own than on the products they do not own (Kahneman et al. 1990: Thaler 1980). Put differently, our findings show a reverse effect in the inferior product situation, such that people instead tend to engage in upward social comparison, with its potential for self-improvement and upgrading (Argo et al. 2006: Wheeler 1966: Wills 1981). Thus, endowment effects may not be a universal phenomenon, but rather are contingent on situational factors. We thereby offer a theoretical refinement of the predictions about endowment effects, especially caused by upward and downward social comparisons.

Social comparison studies posit that downward social comparison will generally result in positive reactions and happy feelings (Aspinwall and Taylor 1993: Bonifield and Cole 2008: Collins 1996: Taylor et al. 1995: Tesser et al. 
1988: Wills 1981). However, in contrast with findings from previous research, we discover that downward social comparisons induce negative, instead of positive reactions toward the promotion of an inferior product from people with a superior product, due to their defensive efforts to maintain their feelings of superiority. Furthermore, social comparison research posits that upward comparison generally leads to negative reactions (Argo et al. 2006: Mussweiler, Gabriel, and Bodenhausen 2000: Tesser and Collins 1988). Yet, we prove that upward comparison can also lead to positive responses toward the promotion of a superior product, as people in an inferior condition feel motivated to engage in self-improvement and upgrading, as hypothesized in previous research (e.g.. Taylor et al. 1995: Wheeler 1966). Accordingly, our findings demonstrate the contingency of $\mathrm{re}^{-}$ actions in downward, as well as upward social comparisons, which depend considerably on situational factors. Our study elaborates, both theoretically and empirically, social comparison theory, especially in the context of reactions during downward and upward social comparisons.

This study suggests the absence of endowment effects toward the ownership of an inferior product. That is, inferior product owners display negative reactions toward their own product: they tend to decrease their positive attitude after being exposed to a superior product's promotion. Owners of an inferior product may not maintain their positive attitude to- ward their own product when faced with an attractive promotion for a superior product. We suggest the reason for this as being the inferiority of the product in the market. Since people may recognize the limitations of their product as an inferior product, they may receive the advertising as information: thus, their attitude becomes a little less positive. At the same time, they may want to defend their attitude of their own product because of their ownership: however, this may not be that strong to defend their attitude. Thus, the endowment effects are weak and absent in the condition of inferior product ownership.

The findings can explain asymmetric quality tier competition in the perspective of consumer behavior. In quality tier competition studies (Allenby and Rossi 1991: Blattberg and Wisniewski 1989: Sivakumar 1995, Sivakumar and Raj 1997: Quelch and Harding 1996), previous research has focused on the relationship between quality and price (e.g., increasing and decreasing price), between price changes and choice, etc. They show consumers' favorable responses when people face price reductions of high- versus low-quality brands. That is, they concentrate on consumers' reactions such as choices, purchases, and so on, depending on changing product attributes.

Different from previous studies' approaches, this study focuses on how people receive information on promotions via considering their own product's position. In detail, people tend to consider their own product position when they 
are exposed to the event, and they show asymmetric position tier competition based on the product's position as a situational factor. As mentioned earlier, people who are considering a relationship between a promoted product and an owned one bring about different responses toward each product with respect to diagnosticity, distortion, and attitude. The findings explain the results of consumers' asymmetric responses via superior versus inferior positions in the market.

With regard to marketing implications, our findings suggest that sales promotions will be more effective for attracting people who currently own an inferior product, but wish to move up. Such promotions are not as effective for attracting people with a superior product, who have a strong motivation to maintain their sense of superiority. These promotions might even induce some unintentional negative reactions from people with a superior product. Thus, for inferior brands to reach consumers in the superior market, their marketing managers may need to turn to approaches other than sales promotions, such as introducing a new brand or sub-brand (e.g.. Genesis from Hyundai) or emphasizing luxury and modern features with competitive prices. However, sales promotions offered by a superior product are generally well received by people who currently possess an inferior product, which make them effective for extending the market of a superior product to those who currently own an inferior product. In this setting, though, marketers must be careful and monitor how current owners react to this kind of sales promotion in order to prevent any negative unintended consequences.

\section{Limitations and Future Research}

To prove the participants level of discomfort and attitude, we measured their levels between, before and after their exposure to the sales promotion in order to show the direction of their attitudinal levels. such as increasing versus decreasing positive attitudes. We used the level of exposure beforehand as a control factor: however, these might have not been best methods for measuring changed levels. In our manipulation check, although we tested each product as superior versus inferior, we did not measure people's comparing tendencies: upward versus downward comparisons. To compensate for this limitation, future researchers should consider these comparison tendencies. We used priming scenarios to prove our hypotheses. To increase the validity of the test, we suggest future researchers to conduct empirical studies with real owners of products, and to test for contradictions of endowment effects with other product categories, such as low-involvement products, low-price products, and so on.

This study tests the hypotheses only with 
the opposite promotion condition (i.e., superior product ownership with an inferior product's promotion: inferior product ownership with a superior product's promotion). Since the method can be limited in proving the effects of $\mathrm{su}^{-}$ perior and inferior conditions for each promotion. we suggest future researchers to test both superior and inferior ownership conditions for each promotion. Future research conducted this way will offer a richer understanding of people's reactions to sales promotions.

〈Received December 31. 2012〉

〈1st Revised March 5. 2013〉

〈2nd Revised May 5. 2013〉

〈Accepted May 14. 2013〉

\section{References}

Aaker, Jennifer L. (2000), “Accessibility or Diagnosticity? Disentangling the Influence of Culture on Persuasion Processes and Attitudes," Journal of Consumer Research, 26 (March), 340-357.

Ahluwalia, Rohini (2000), "Examination of Psychological Processes Underlying Resistance to Persuasion," Journal of Consumer Research, 27 (September), 217-232.

Ahluwalia, Rohini, Robert E. Burnkrant, and H. Rao Unnava (2000), “Consumer Response to Negative Publicity: The Moderating Role of Commitment," Journal of
Marketing Research, 37 (May), 203-214. Allenby, Greg and Peter Rossi (1991), “Quality Perceptions and Asymmetric Switching Between Brands," Marketing Science, 10 (Summer), 185-204.

Argo, Jenifer J.. Katherine White, and Darren W. Dahl (2006), “Social Comparison Theory and Deception in the Interpersonal Exchange of Consumption Information," Journal of Consumer Research, 33 (June), 99-108.

Aspinwall, Lisa G. and Shelley E. Taylor (1993), "Effects of Social Comparison Direction, Threat, and Self-Esteem on Affect, SelfEvaluation, and Expected Success," Journal of Personality and Social Psychology, 64 (5), 708-722.

Baker, William E. (2001), “The Diagnosticity of Advertising Generated Brand Attitudes in Brand Choice Contexts," Journal of Consumer Psychology, 11 (2), 129-139.

Blattberg, Robert C. and Ken Wisniewski (1989), "Price Induced Patterns of Competition," Marketing Science, 8 (Fall), 291-310.

Bonifield, Carolyn and Catherine A. Cole (2008), "Better Him than Me: Social Comparison Theory and Service Recovery," Journal of the Academy of Marketing Science, 36. 565-577.

Carmon, Ziv and Dan Ariely (2000), “Focusing on the Forgone: How Value Can Appear so Different to Buyers and Sellers," Journal of Consumer Research, 27, 360-370.

Chernev, Alexander (2004), "Goal Orientation 
and Consumer Preference for the Status Quo," Journal of Consumer Research, 31 (3), 557-565.

Collins, Rebecca L. (1996), "For Better or Worse:

The Impact of Upward Social Comparison on Self-Evaluations," Psychological Bulletin, 119 (1), 51-69.

Elliot, Andrew J. and Patricia G. Devine (1994), "On the Motivational Nature of Cognitive Dissonance: Dissonance as Psychological Discomfort," Journal of Personality and Social Psychology, 67 (3), 382-394.

Feldman, Jack M. and John G. Lynch (1988), "Self-Generated Validity and Other Effects of Measurement on Belief, Attitude, Intention and Behavior," Journal of Applied Psychology, 73, 421 - 535.

Festinger, Leon (1954), “A Theory of Social Comparison Processes," Human Relations, 7, 117-140.

Hong, Seong Tae, Won-Jun Lee, Chong-Dae Kim, and Byoung-Jai Kim (2012), "A Study on Factors Influencing Perceived Overall Quality and Performance in Financial Services," Asia Marketing Journal, 13 (4), 191-212.

Im, Meeja (2012), "Discount Presentation Framing and Bundle Evaluation: The Effects of Consumption Benefit and Perceived Uncertainty of Quality," Asia Marketing Journal, 14 (1), 53-81.

Jiang. Zhenhui and Izak Benbasat (2004), "Virtual Product Experience: Effects of Visual and
Functional Control of Products on Perceived Diagnosticity and Flow in Electronic Shopping," Journal of Management Information Systems, 21 (3), 111-147.

Jain, Shailendra Pratap and Durairaj Maheswaran (2000), "Motivated Reasoning: A Depthof-Processing Perspective," Journal of Consumer Research, 26 (4), 358-371.

Kahneman, Daniel, Jack L. Knetsch, and Richard H. Thaler (1990), “Experimental Tests of the Endowment Effect and the Coase Theorem," Journal of Political Economy, 98 (6), 1325-1348.

Kahneman, Daniel, Jack L. Knetsch, and Richard H. Thaler (1991), "The Endowment Effect, Loss Aversion, and Status Quo Bias," Journal of Economic Perspectives, 5 (December). 1325-1347.

Kahneman, Daniel and Amos Tversky (1979), "Prospect Theory: An Analysis of Decision under Risk," Econometrica: Journal of the Econometric Society, 42 (2), 263-291.

Kemmelmeier, Markus (2004), "Separating the Wheat From the Chaff: Does Discriminating Between Diagnostic and Nondiagnostic Information Eliminate the Dilution Effect?" Journal of Behavioral Decision Making. 17 (3), 231-243.

Knetsch, Jack L. and John A. Sinden (1984), "Willingness to Pay and Compensation Demanded: Experimental Evidence of An Unexpected Disparity in Measures of Value," Quarterly Journal of Economics, 99, 507- 
521.

Kunda, Ziva and Sinclair, Lisa (1999), "Motivated Reasoning with Stereotypes: Activation, Application, and Inhibition," $P S y^{-}$ chological Inquiry, 10 (1), 12-22.

Lynch Jr., John G., Howard Marmorstein, and Michael F. Weigold (1988), “Choices from Sets Including Remembered Brands: Use of Recalled Attributes and Prior Overall Evaluations," Journal of Consumer Research, 15, 169-184.

Menon, Geeta, Priya Raghubir, and Norbert Schwarz (1995), “Behavioral Frequency Judgments: An Accessibility-Diagnosticity Framework," Journal of Consumer Research, 22 (September), 212-228.

Mussweiler, Thomas, Shira Gabriel, and Galen V. Bodenhausen (2000), “Shifting Identities as a Strategy for Deflecting Threatening Social Comparisons," Journal of Personality and Social Psychology, 79 (3), 398-409.

Park, Sojin (2011), “The Effects of Bundle Price Discount Framing and Message Framing on Consumers' Evaluation of Bundle Component," Asia Marketing Journal, 13 (3), 55-77.

Quelch, John A. and David Harding (1996), "Brands Versus Private Labels: Fighting to Win," Harvard Business Review, 74 (January/February), 99-109.

Russo, J. Edward, Victoria Husted Medvec, and Margaret G. Meloy (1996), “The Distortion of Information during Decisions," Organi- zational Behavior and Human Decision Processes, 66 (April), 102-110.

Russo, J. Edward, Margaret G. Meloy, and Victoria Husted Medvec (1998), "Predecisional Distortion of Product Information," Journal of Marketing Research, 35 (November), 438-452.

Sivakumar, K. (1995), “Quality-tier Competition and Optimal Pricing," Journal of Business Research, 33 (3), 251-260.

Sivakumar, K., and S. P. Raj (1997), “Quality Tier Competition: How Price Change Influences Brand Choice and Category Choice," Journal of Marketing, 71-84.

Taylor, Shelley E. and M. Lobel (1989), “Social Comparison Activity Under Threat: Downward Evaluation and Upward Contacts," Psychological Review, 96, 569-975.

Taylor, Shelley E., Efrat Neter, and Heidi A. Wayment (1995), "Self-Evaluation Processes," Personality and Social Psychology Bulletin, 21. 1278-1287.

Tesser. Abraham and James E. Collins (1988), "Emotion in Social Reflection and Comparison Situations: Intuitive, Systematic, and Exploratory Approaches," Journal of Personality and Social Psychology, 55 (5), 695-709.

Tesser, Abraham, Murray Millar, and Janet Moore (1988), “Some Affective Consequences of Social Comparison and Reflection Processes: The Pain and Pleasure of Being Close," Journal of Personality and Social Psychology, 54 (1), 49-61. 
Thaler, Richard (1980), "Toward a Positive Theory of Consumer Choice," Journal of Economic Behavior and Organization, 1 (March), 39-60. Wheeler, Ladd (1966), "Motivation as a Determinant of Upward Comparisons," Journal of Experimental Social Psychology, 1, 27-31.

Wills, Thomas A. (1981), "Downward Comparison Principles in Social Psychology," Psychological Bulletin, 90 (2), 245-271.

Wood, Joanne. V. (1989), "Theory and Research Concerning Social Comparisons of Personal Attributes," Psychological Bulletin, 106, 231-248.
Wood, Joanne. V. and Kathryn L. Taylor (1991). "Serving Self-Relevant Goals Through Social Comparison," In J. Suls and T.A. Wills (Eds.), Social Comparison: Contemporary Theory and Research (23-50). Hillsdale, NJ: Lawrence Erlbaum.

Zhang, Ying and Ayelet Fishbach (2005), "The Role of Anticipated Emotions in the Endowment Effect," Journal of Consumer Psychology, 15 (4), 316-324. 